\title{
Electrofinishing of metals using eutectic based ionic liquids
}

\author{
A. P. Abbott*1, K. S. Ryder ${ }^{1}$ and U. König ${ }^{2}$
}

\begin{abstract}
Ionic liquids are molten salts that have low melting points. This review concentrates upon eutectic mixtures of quaternary ammonium salts and metal salts (usually halides). These so-called eutectic based ionic liquids can be used for the electrodeposition and dissolution of a wide range of metals and alloys. The review highlights the technological challenges involved in the application of ionic liquids to metal finishing.
\end{abstract}

Keywords: Ionic liquids, Metal deposition, Electropolishing, Aluminium, Chromium, Zinc alloys

\section{Introduction}

With over 150 years of experience, the metal finishing industry could be said to be mature. An alternative perspective is that with such a wide range of metals to choose from, the limited pallet of systems that are currently commercially available means that the current technology is in urgent need of an overhaul to open new markets and products. The industry also faces key challenges. Its main markets are the deposition of $\mathrm{Zn}$, $\mathrm{Ni}, \mathrm{Cr}, \mathrm{Cu}, \mathrm{Ag}$ and $\mathrm{Au}$. Legislation is currently limiting the application of $\mathrm{Cr}$ and the Ni plating sector will be affected by toxicity issues and the rising price of metals.

Almost the entire electroplating sector is currently based on aqueous solutions generally (acidic or basic) although some specialist applications use organic solvents. ${ }^{1}$ More exotic metals can be deposited using plasma or chemical vapour deposition techniques (PVD and CVD). While this allows coating of a wide range of substrates (metal, plastic, glass, ceramic, etc.) not only with metal but also with alloys or compounds (oxide, nitride, carbide, etc.) the high capital investment and large running costs have limited it to niche markets with high value products.

The key solvent requirements for plating solutions are low cost, non-flammable, high solubility of electrolytes, high conductivities resulting in low ohmic losses and good throwing power, high solubility of metal salts, high rates of mass transfer and high electrochemical stability. Water fulfils all of these roles except the last and as such will remain the main stay of the metal plating industry for the foreseeable future. However, issues exist such as the limited potential windows, gas evolution leading to hydrogen embrittlement, passivation of substrates, electrodes and deposits, and hazardous complexing agents, such as cyanide means that since water must be

\footnotetext{
${ }^{1}$ Scionix Laboratory, Department of Chemistry, University of Leicester, Leicester, LE1 7RH, UK

'Zentralverband Oberflächentechnik e.V. Max-Volmer-Straße 1, D-40724 Hilden, Germany

*Corresponding author, email apa1@le.ac.uk
}

returned to the environment eventually contamination is inevitable.

Many key technological goals exist including replacement of environmentally toxic metal coatings, deposition of new alloys and semiconductors and new coating methods for electronegative metals. The main driving force for non-aqueous electrolytes has been the desire to deposit refractory metals, such as $\mathrm{Ti}, \mathrm{Al}$ and $\mathrm{W}$. These metals are abundant and excellent for corrosion resistance. It is, however, the stability of their oxides that makes these metals difficult to extract from minerals and apply as surface coatings.

Over the last 10 years an alternative fluid has been developed called an ionic liquid which is defined as 'an ionic material that is liquid below $100^{\circ} \mathrm{C}^{\prime}{ }^{2}$ While this may sound like an oxymoron because ionic materials usually have high melting points a wide range of organic salts are available and have, in some cases, melting points down to $-40^{\circ} \mathrm{C}$. Ionic liquids have significant properties that makes them ideal for metal processing:

(i) wide potential windows

(ii) high solubility of metal salts

(iii) avoidance of water and metal/water chemistry

(iv) high conductivity compared to non-aqueous solvents.

The use of ionic liquids heralds not only the ability to electrodeposit metals that have until now been impossible to reduce in aqueous solutions but also the capability to engineer the redox chemistry and control metal nucleation characteristics. It has been estimated that there are more than $10^{18}$ ionic liquids possible and while this has the obvious advantage of flexibility, it also adds extreme complexity to the optimisation. ${ }^{3}$ Ionic liquids contain large, non-symmetric ions that have low lattice energy and hence low melting points. The most commonly used cations for metal finishing are imidazolium, pyridinium and choline based. The structures of these are shown in Fig. 1.

Ionic liquids have been classified by their anionic species into so called first and second generation liquids ${ }^{2}$ where first generation liquids have complex anions formed between a Lewis basic anion, e.g. $\mathrm{Cl}^{-}$ with a Lewis acid metal salt or a Brønsted acid hydrogen 


\begin{tabular}{|c|c|c|}
\hline Imidazolium & Pyridinium & Choline \\
\hline $\begin{array}{rl}\mathbf{R}_{1}=\mathrm{CH}_{3} \mathrm{R}_{2}=\mathrm{Et} & \mathrm{R}_{2} \\
\mathbf{R}_{2}=\mathrm{Bu} & \mathrm{emmim} \\
\mathrm{bmim}\end{array}$ & $\mathrm{R}$ & $\mathrm{HOC}_{2} \mathrm{H}_{4} \mathrm{~N}^{+}\left(\mathrm{CH}_{3}\right)_{3}$ \\
\hline & $\mathrm{R}=\mathrm{Bu} \quad$ bpy & \\
\hline
\end{tabular}

\section{Cations used in ionic liquids}

bond donor. These are, in effect, eutectic mixtures of the two components. Second generation ionic liquids have discrete anions such as $\mathrm{BF}_{4}{ }^{-}, \mathrm{PF}_{6}^{-}$and $\mathrm{SCN}^{-}{ }^{2}$ Academic studies have concentrated on second generation ionic liquids as they tend to have lower viscosities and are chemically easier to describe, consisting of just one type of anion. The majority of work has focused on imidazolium, pyridinium and quaternary ammonium salts. Again, the cation of choice has been ethyl, methyl imidazolium due again in part to the low viscosity and concomitant higher conductivity. These liquids are now available through distributors such as BASF and Merck although the high cost currently prohibits their application to large scale applications such as metal plating. The fact that they are new materials also necessitates their registration under legislation such as $\mathrm{REACH}$ which still requires significant toxicological testing. A recent review by Seddon highlights the current state of applications for ionic liquids. ${ }^{4}$

Before the reader is, however, dispirited it must be appreciated that this is a revolutionary enabling technology which will inevitably permeate into the metal plating industry. Deposition of pure metals and alloys of over 35 metals have been achieved from ionic liquids. While no electrolytic coatings have yet been commercialised on a large scale using this technology the results below show that the first technologies are currently coming to market and the next decade will, in the authors' opinion, certainly see their adoption in a range of applications. The metals deposited to date are shown schematically in Fig. 2.

Several recent reviews have covered the use of ionic liquids in electrochemistry ${ }^{5-10}$ and the most comprehensive of these is the book by Ohno, ${ }^{11}$ which not only covers the fundamental aspects but also a wide range of applications including lithium batteries, photoelectrochemical cells, fuel cells and capacitors. Reviews by Compton $^{12}$ and Endres are also recommended for their coverage of fundamental electrochemistry and electrodeposition. ${ }^{9,13}$ They are also focussed primarily on discrete anions. Readers who are new to the area are directed to a recent book on the topic which is the definitive background to the subject containing all of the work published in the area. ${ }^{14}$ The book also contains practical issues and plating protocols.

The purpose of this review is to focus on eutectic based ionic liquids which are closer to market and, in general, are probably the most easily adopted by the metal finishing industry from a cost, registration and handling perspective. These can be described by the general formula

$$
\mathrm{Cat}^{+} \mathrm{X}^{-} z \mathrm{Y}
$$

where $\mathrm{Cat}^{+}$is in principle any ammonium, phosphonium or sulphonium cation, $\mathrm{X}$ is generally a halide anion (usually $\mathrm{Cl}^{-}$). The complex anionic species are formed

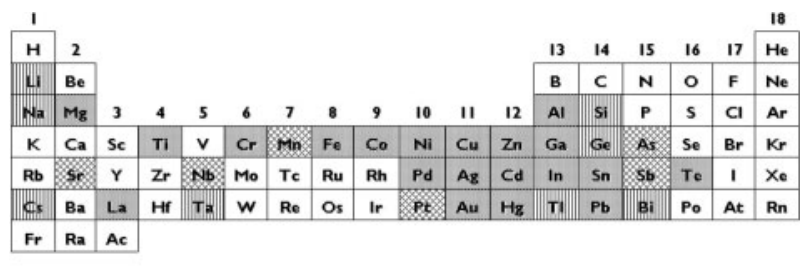

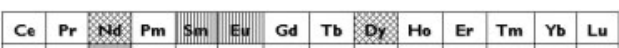
\begin{tabular}{|l|l|l|l|l|l|l|l|l|l|l|l|l|l|}
\hline Th & Pa & U & Np & Pu & Am & Cm & Bk & Cr & Es & Fm & Md & No & Lr \\
\hline
\end{tabular}

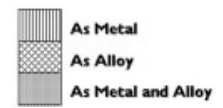

2 Metals and alloys deposited using ionic liquids

between $\mathrm{X}^{-}$and either a Lewis or Brønsted acid Y $(z$ refers to the number of $\mathrm{Y}$ molecules that interact with the anion). There is a significant depression of freezing point at the eutectic composition that can be $\sim 300^{\circ} \mathrm{C}$. The ionic liquids thus formed can be subdivided into three types depending on the nature of the complexing agent used

Type I eutectic $\mathrm{Y}=\mathrm{MCl}_{\mathrm{x}}, \mathrm{M}=\mathrm{Zn},{ }^{15-17} \mathrm{Sn},{ }^{18} \mathrm{Fe},{ }^{18}$ $\mathrm{Al},{ }^{19} \mathrm{Ga}^{20} \mathrm{In}^{21}$

Type II eutectic $\mathrm{Y}=\mathrm{MCl}_{\mathrm{x}} \cdot y \mathrm{H}_{2} \mathrm{O}, \mathrm{M}=\mathrm{Cr},{ }^{22} \mathrm{Co}, \mathrm{Cu}$, $\mathrm{Ni}, \mathrm{Fe}$

Type III eutectic $\mathrm{Y}=\mathrm{RZ}, \mathrm{Z}=\mathrm{CONH}_{2},{ }^{23} \mathrm{COOH},{ }^{24}$ $\mathrm{OH}^{2}$

Much of the work has used choline chloride $\left[\mathrm{HOC}_{2} \mathrm{H}_{4} \mathrm{~N}\left(\mathrm{CH}_{3}\right)_{3} \mathrm{Cl}\right][\mathrm{ChCl}]$ as the quaternary ammonium salt, CatX primarily due to lack of toxicity and comparatively low cost. It is classified as a provitamin in Europe and is made on the megatonne scale as an animal feed supplement. It is produced by a one step gas phase reaction between $\mathrm{HCl}$, ethylene oxide and trimethylamine and as such involves the production of negligible ancilliary waste.

A network of 33 companies, academic institutions and trade associations has been working together to research, scale up and commercialise electroplating and electropolishing processes based around these novel ionic liquids. To date two of these processes are close to commercialisation and a further three are in scale-up testing. The IONMET network is an integrated project funded under FP6 which started in April 2005. ${ }^{26}$ The overall objective of the project is the introduction of a breakthrough technology with the potential to transform the scope and competitiveness of industrial metal finishing processes. The new technology will introduce a novel generic group of ionic liquid solvents which will provide the tools to significantly transform the innovative capability of the huge number of traditional manufacturing SMEs involved directly in the surface finishing and printed circuit board manufacturing industry sectors in particular. The radical new generic technology will enable the introduction of a large number of totally new products and processes, which cannot be produced using existing technology.

The production of eutectic based ionic liquids involves just the simple mixing of the two components with moderate heating. This maintains a comparatively low cost with respect to second generation ionic liquids and permits large scale applications, such as metal deposition. $\mathrm{ChCl}$ based eutectics are the closest to 
commercialisation in the metal finishing industry and as such they highlight the benefits and difficulties associated with process scale-up.

Most reviews to date have focused on the ionic liquids and the metals that can be deposited from them. In this review the background literature will be discussed in terms of the end application.

One of the main issues associated with process development is the large number of variables that can be independently varied to change the deposition characteristics. These include:

(i) temperature

(ii) cation

(iii) anion

(iv) electrolytes

(v) metal salts

(vi) complexing agents

(vii) diluents

(viii) anode material

(ix) brighteners

(x) pre-treatment protocol.

The effect of each parameter is discussed in general terms in a recent review. Ionic liquids have a number of applications in metal finishing including electrolytic deposition, electroless deposition and electrodissolution of metals.

\section{Electrolytic deposition of metals}

\section{Aluminium}

Metal finishing processes using traditional electrolytes in aqueous solutions have many limitations and disadvantages. The range and quality of coatings that can be produced is limited by the chemistry of the plating baths. Metal ions with reduction potentials below that of the $\mathrm{H}^{+}$have either low current efficiencies or cannot be electroplated at all from aqueous solutions. This precludes the electrodeposition of many important metals including $\mathrm{Al}, \mathrm{Mg}, \mathrm{W}$ and $\mathrm{Ti}$ from aqueous baths. In this sense, the main advantage of using ionic liquids solvents over aqueous baths is that they allow the electroplating of the aforementioned metals, including aluminium.

The electrodeposition of aluminium in organic solutions is commercially carried out using the SIGALprocess, ${ }^{27,28}$ which uses toluene and triethylaluminium, but the volatility and flammability of the electrolyte makes it difficult to implement. The clear strategic importance of aluminium is the reason why the field of ionic liquids came to the fore in the first place. The concept of ionic liquids originated from concerted attempts to make eutectics of aluminium chloride with accessible melting points. Eutectic mixtures of $\mathrm{KCl}$ with $\mathrm{AlCl}_{3}(67 \mathrm{~mol} .-\%)$ for example have a melting point of $128^{\circ} \mathrm{C}^{29}$ These are well known to contain mixtures of $\mathrm{AlCl}_{4}{ }^{-}$and $\mathrm{Al}_{2} \mathrm{Cl}_{7}^{-}$and it is this charge delocalisation that lowers the lattice energy and produces the concomitant decrease in the melting point. The first major studies in ionic liquids occurred when $\mathrm{KCl}$ was substituted by firstly pyridinium ${ }^{30,31}$ and then later imidazolium chloride. ${ }^{32}$

Reaction of a quaternary ammonium halide salt $\mathrm{Q}^{+} \mathrm{X}^{-}$with $\mathrm{AlCl}_{3}$ results in the formation of a salt with the composition $\mathrm{Q}^{+} \mathrm{AlCl}_{4}{ }^{-}$although, in general, more than one anion species is produced, depending on the relative proportions of the salt and $\mathrm{AlCl}_{3}$. If the mole fraction of $\mathrm{AlCl}_{3}$ is less than 0.5 the ionic liquids are referred to as Lewis basic whereas a mole fraction greater than 0.5 produces Lewis acidic melts. In Lewis acidic melts the following equilibria occur

$$
\begin{aligned}
& 2 \mathrm{AlCl}_{3}+\mathrm{Q}^{+} \mathrm{Cl}^{-} \rightleftharpoons \mathrm{Al}_{2} \mathrm{Cl}_{7}^{-}+\mathrm{Q}^{+} \\
& 2 \mathrm{Al}_{2} \mathrm{Cl}_{7}^{-} \rightleftharpoons \mathrm{AlCl}_{4}^{-}+\mathrm{Al}_{3} \mathrm{Cl}_{10}^{-} \\
& \mathrm{Al}_{2} \mathrm{Cl}_{7}^{-} \rightleftharpoons \mathrm{AlCl}_{3}+\mathrm{AlCl}_{4}^{-}
\end{aligned}
$$

The mechanism of growth depends in part on the relative speciation and the mass transport of species to the electrode surface. These fluids have a viscosity of $\sim 20 \mathrm{mPa}$ s and a conductivity of $\sim 15 \mathrm{mS} \mathrm{cm}^{-1}$ making them eminently suitable for metal deposition. ${ }^{32}$ While the conductivity may seem lower than most electroplaters are accustomed to using it must also be appreciated that the liquids are $5-10 \mathrm{~mol} \mathrm{~L}^{-1}$ in aluminium.

Some of the first concerted studies into aluminium electrodeposition using first generation ionic liquids were those of Robinson and Osteryoung ${ }^{33,34}$ who described the electrodeposition of aluminium on $\mathrm{Pt}$ and glassy carbon from Lewis acidic butylpyridinium chloride/ $/ \mathrm{AlCl}_{3}$ melts. Deposits could not be obtained using Lewis basic melts and we have proposed that this is due to the lower concentration of aluminium in the double layer. It was found that poor deposits were obtained without the addition of a modifier for which the authors used benzene. They were able to deposit $15 \mu \mathrm{m}$ thick aluminium on a brass substrate. Imidazolium based liquids were used by Lay and Skyllas-Kazacos ${ }^{35}$ for aluminium deposition on a $\mathrm{W}$ electrode. They found that the deposition mechanism was controlled by a mixture of mass transport and nucleation. Hussey et al. ${ }^{36}$ studied a Lewis acidic $\mathrm{AlCl}_{3} /$ 1-ethyl-3-methyl-imidazolium chloride-based mixture and were able to deposit 24-30 $\mu \mathrm{m}$ layers of aluminium although again these were poorly adherent without the addition of benzene. Abbott et al. ${ }^{37}$ used benzyltrimethylammonium chloride $/ \mathrm{AlCl}_{3}$ to deposit aluminium on a variety of substrates. This electrolyte was found to be less water sensitive, easier to purify than the imidazolium and pyridinium liquids. More thorough reviews of aluminium deposition are given elsewhere.

With over 30 years of research it may be questioned why this technology has not been commercialised. Partly this is due to misrepresentation of data published in the literature. While chloroaluminate liquids are hygroscopic they are eminently easier to use than many other aluminium sources such as triethylaluminium. Ionic liquids also require different protocols to aqueous plating, but once these are developed the procedure is relatively simple to apply and operate.

Within the IONMET project, Fundacion Inasmet (San Sebastian, Spain), Technical University of Clausthal (Germany), University of Leicester (UK) and C-Tech Innovation (UK) have developed a process for aluminium electroplating on steel samples based on imidazolium type ionic liquids. Uniform, adherent, corrosion resistant aluminium coatings have been obtained with no evidence of red corrosion after $800 \mathrm{~h}$ of salt spray fog corrosion testing (for thicknesses of $\sim 10 \mu \mathrm{m}$ ). Bright aluminium electroplating is also feasible. At this stage of 


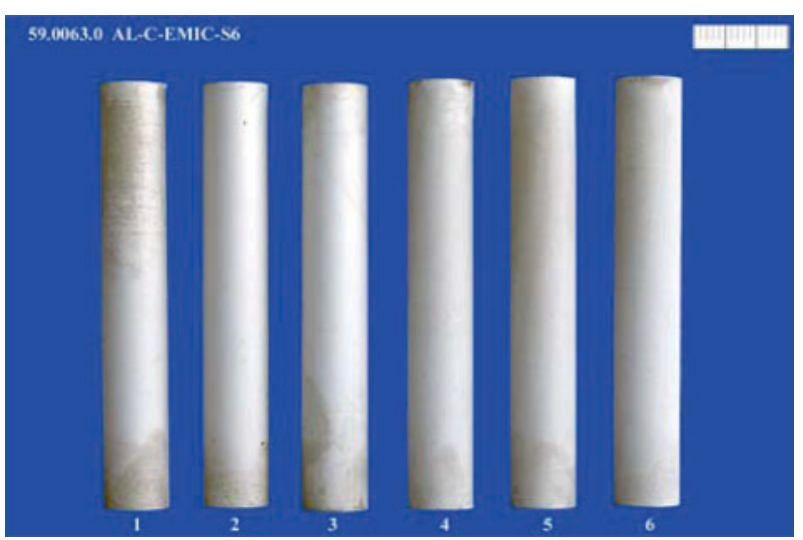

3 Aluminium deposition on mild steel under different pretreatment regimes: samples shown were electroplated under identical conditions but initial chemical pretreatment was varied to facilitate adhesion tests; all samples show even, homogeneous Al deposit

the project, a significant knowledge has been achieved both in the fundamentals and in the control of the electrodeposition process parameters. A pilot rig was constructed and is currently being operated to allow Al coated samples up to $400 \mathrm{~cm}^{2}$ to be coated within $37 \mathrm{~L}$ of plating solution. Uniform, adherent, corrosion resistant aluminium coatings on steel components have been achieved as evidenced by the pieces shown in Fig. 3. The pilot plant for the process is shown in Fig. 4. Significant testing has still to be carried out, but it is realistic that such a process could be commercialised during 2009.

\section{Chromium}

Hard chromium deposition using hexavalent chromium solution is a mature industry although the toxicity of hexavalent chromium is a significant concern to the industry. Currently in Europe the maximum concentration in liquid effluent has been fixed at $\sim 0 \cdot 1 \mu \mathrm{g} \mathrm{L}^{-1}$. Many research programmes through the world have been developed to define, test and commercialise processes as a substitute for hard chromium plating using hexavalent chromium. For instance hard chromium alternative team (HCAT) which is a joint programme research between the US Department of Defence and The Canadian Ministry of Defence has been developed to study the substitution of hexavalent chromium in military aeronautic applications using a high velocity oxygen fuel process. ${ }^{38}$

The electrodeposition of crack free chromium has been demonstrated from an ionic liquid formed between choline chloride and $\mathrm{CrCl}_{3} \cdot 6 \mathrm{H}_{2} \mathrm{O} .{ }^{22}$ While it might be thought that this is a concentrated aqueous solution the water molecules are all either coordinated to the $\mathrm{Cr}$ centre or associated with the free chloride ions. This means that the activity of water is low and the process can be operated at a very high current efficiency (typically $>90 \%$ ). The viscosity and conductivity are higher than those of many eutectic based ionic, the latter typically $10 \mathrm{mS} \mathrm{cm}{ }^{-1}$. The addition of lithium chloride allows the deposition of a crack free, nanocrystalline black chromium film that affords excellent corrosion resistance. ${ }^{39}$ Soluble chromium anodes have been demonstrated for the first time and this further enhances the sustainability of the process.

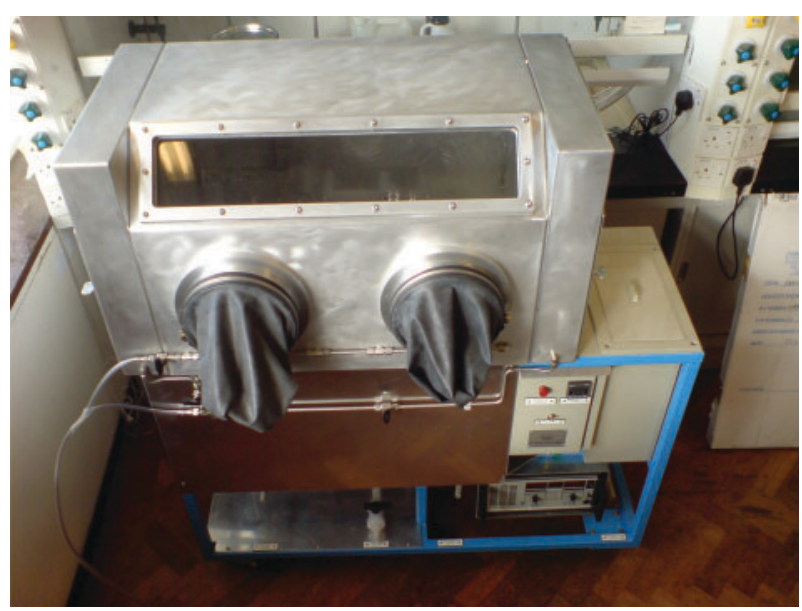

4 Pilot plant for deposition of aluminium: plating tank volume $40 \mathrm{~L}$, constant current or constant potential regimes are both possible

An ionic liquid based on chromium (III) chloride and choline chloride has been used to obtain metallic chromium on a steel substrate with interesting properties. The coatings were initially always black and showed little mechanical strength. Subsequent work by Benaben et al., (ARMINES, St. Etienne, France) in the IONMET project optimised the bath components and operating conditions. This permitted the electrolytic deposition of both hard and bright chromium plate from trivalent chromium containing ionic liquids. The temperature of the electrolysis has been fixed at $\sim 40^{\circ} \mathrm{C}$, and chromium deposition has been made on a variety of different substrates including mild steel. The surface is pretreated in a similar manner to that in aqueous plating, i.e. polishing, degreasing, anodic etching in dilute sulphuric acid. The average current density is $15 \mathrm{~A} \mathrm{dm}^{-2}$ and the rate of deposition is about 0.7 to $1 \mu \mathrm{m} \mathrm{min}{ }^{-1}$ depending on the conditions. Measurements on microhardness have shown that under a load of $100 \mathrm{~g}$, the Vickers microhardness is $\sim 700 \mathrm{HV}$. An interesting point in this field is that after heat treatment $\left(400^{\circ} \mathrm{C} / 1 \mathrm{~h}\right.$, under nitrogen atmosphere), the microhardness increases from 700 to $1400-1500 \mathrm{HV})$. In fact, the influence of temperature on microhardness seems to be the same as for other hard trivalent chromium. X-ray diffraction tests have shown that during the heat treatment, there is an evolution of the structure between simple cubic to FCC structure. Tests on the durability of trivalent chromium electrolytic solutions have been made for over a year and these suggest that the process is robust. Some tests have been made in an industrial environment and results have confirmed the validity of the process. This process is currently being scaled up to $500 \mathrm{~L}$ within the IONMET programme. Figure 5 shows some samples of decorative chromium on steel from ionic liquids developed by I Fundacion Inasmet (San Sebastian, Spain). To date no details have been published about the specific additives or process conditions used.

\section{Zinc}

Zinc is fundamentally important to the metal finishing industry primarily because of its environmental compatibility, cost and corrosion protection properties. While aqueous technology is clearly advanced and produces a very good coating the study of zinc deposition in ionic 


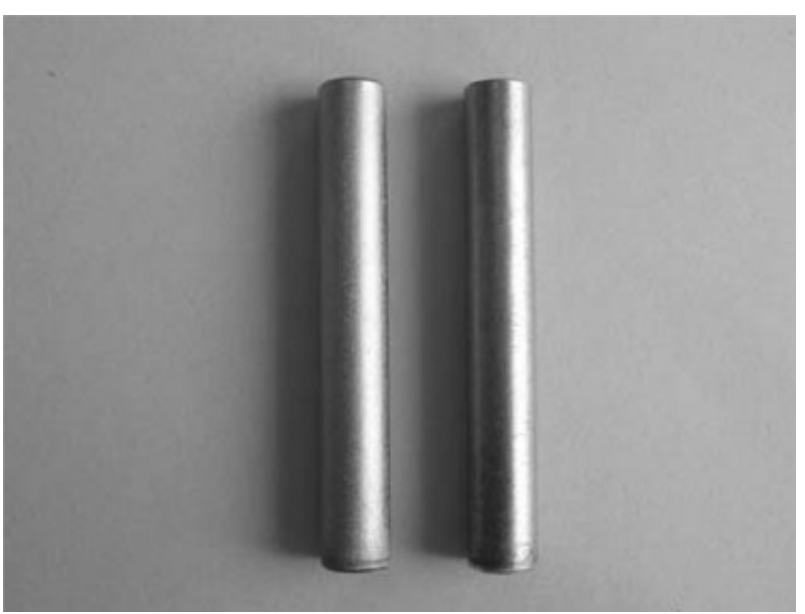

5 Examples of hard chromium deposits on XC38 steel (left) and 304 stainless steel (right) (typical thickness: 25-30 $\mu \mathrm{m}$ ): two samples were coated under same conditions at constant potential in $\mathrm{CrCl}_{3} \cdot\left(\mathrm{H}_{2} \mathrm{O}\right) \mathrm{ChCl}$ based eutectic liquid

liquids is an important stepping stone to the production of zinc alloys.

Zinc chloride forms eutectics in a similar manner to aluminium chloride. It forms complex chlorozincate anions, $\mathrm{ZnCl}_{3}{ }^{-}, \mathrm{Zn}_{2} \mathrm{Cl}_{5}{ }^{-}$and $\mathrm{Zn}_{3} \mathrm{Cl}_{7}{ }^{-}$with quaternary ammonium halides. ${ }^{18}$ The liquids are more viscous and less conducting than the corresponding aluminium systems. This is due to the higher melting point of the eutectic resulting from the higher melting point of the pure metal halide. In general the melting point, viscosity and conductivity of all eutectic systems are related to the melting point of the constituent components. Type I eutectics also form with $\mathrm{FeCl}_{3},{ }^{40} \mathrm{SnCl}_{2}, \mathrm{GaCl}_{3}{ }^{20}$ and $\mathrm{InCl}_{3}{ }^{21}$ and pure metal can be deposited from the eutectic mixture.

Chlorozincate liquids are easier to make and handle than the corresponding chloroaluminates as they are less susceptible to hydrolysis. The electrochemistry of these liquids is dominated by the complex anions present in the liquid which depends on the relative Lewis acidity. Hsiu et al. used FAB MS to show that some hydrolysis of zinc Lewis basic melts does however occur. ${ }^{15}$

The potential limits of $\mathrm{EMIM} / \mathrm{ZnCl}_{2}$ in the molar ratio range $3: 1$ to $1: 3$ were also studied and found to be $\sim 2 \mathrm{~V}$ in the Lewis acidic region; the negative potential limit is due to the deposition of metallic zinc and the positive potential limit is due to the oxidation of the chlorozincate complexes to form chlorine. ${ }^{41}$ In the Lewis basic region the potential window was $\sim 3 \mathrm{~V}$ as the $\mathrm{Zn}$ could not be reduced and the cathodic process became the reduction of $[\mathrm{EMIM}]^{+}$in an analogous manner to the basic chloroaluminate melts. In the Lewis acidic melts underpotential deposition (UPD) of zinc was observed on Pt and Ni electrodes. The potential window and UPD of zinc in Lewis acidic choline chloride $(\mathrm{ChCl}) / \mathrm{ZnCl}_{2}$ was found to be exactly the same as the corresponding EMIMCl system suggesting that the cation has little or nothing to do with the electrochemistry of the liquid.

An in depth study of the deposition mechanism was carried out by Sun et al. who studied the 1:1 EMIMCl/ $\mathrm{ZnCl}_{2}$ system at various temperatures on glassy carbon (GC), nickel and platinum electrodes. ${ }^{42}$ The GC electrode required the largest overpotential for deposition. The stripping process showed a single peak on GC, whereas two oxidation processes were observed on $\mathrm{Ni}$ separated by $\sim 0.6 \mathrm{~V}$. It was proposed that the more positive oxidation process corresponded to the dissolution of an intermetallic compound formed during electrodeposition.

Chronoamperometry on the GC and $\mathrm{Ni}$ electrodes showed that the electrodeposition of zinc proceeded by a three-dimensional instantaneous nucleation and growth process. The results also suggested that the growth process is under mixed diffusion and kinetic control. The deposits consisted of adherent hexagonal grains with a size of $4-5 \mu \mathrm{m}$ covered by numerous, poorly adherent small needles deposits formed at larger overpotentials were poorly adherent flakes and increasing the temperature from 50 to $80^{\circ} \mathrm{C}$ had little effect on the morphology.

Sun also studied the effect of adding a diluent to a liquid to improve mass transport in an analogous manner to Osteryoung for aluminium. ${ }^{43}$ Propylene carbonate was added from 20 to $60 \%(\mathrm{v} / \mathrm{v})$ and found to have little effect on the voltammetry. The same instantaneous three-dimensional growth was observed under mixed diffusion and kinetic control. The propylene carbonate did however lead to an improvement in deposit morphology compared to the neat melt and no small needles were observed. Increasing the deposition potential decreased the grain size by increasing the nucleation density. The grain size was also affected by diluent concentration with larger grains forming with higher propylene carbonate content although this also increased the grain size distribution. Grain size could also be increased by increasing the temperature of the melt.

The deposition of zinc from Lewis basic EMIMBr/ $\mathrm{ZnBr}_{2}$ eutectics was studied at $120^{\circ} \mathrm{C}$ together with the effect of adding ethylene glycol as a diluent. ${ }^{43,44}$ Choronoamperometry showed that the overpotential was related to the progressive nucleation with diffusion controlled growth of the nuclei. The nucleation loop observed using cyclic voltammetry disappeared on adding more than 45 mol.- $\%$ ethylene glycol to the ionic liquid. The cathodic current increased with increasing ethylene glycol content which was thought to be due to the increased dissociation of EMIMBr to $\mathrm{EMIM}^{+}$cation and $\mathrm{Br}^{-}$, and formation of $\mathrm{ZnBr}_{4}{ }^{2-}$ in the molten salt was increased. The study was further extended to investigate the effect of a range of dihydric alcohols (ethylene glycol, 1,3-propanediol, 1,2-butanediol, or 1,3-butanediol). The smoothness and colour of the deposits was improved by the addition of dihydric alcohols and it also resulted in an increase in the cathodic current efficiency at high current density. Of the alcohols studied, ethylene glycol gave the best results.

The same group studied the effect of water on zinc deposit morphology in the same ionic liquid in the EMIMBr/ZnBr 2 (70:30 mol.- $\%)$. Smooth layers of silver coloured $\mathrm{Zn}$ were obtained at cathodic current densities $<100 \mathrm{~A} \mathrm{~m}^{-2}$, whereas smooth grey $\mathrm{Zn}$ layers were electrodeposited at cathodic current densities $>150 \mathrm{~A} \mathrm{~m}^{-2}$. The molten salt with a water content of less than $10 \mathrm{ppm}$ was superior to the molten salt with a water content of $400 \mathrm{ppm}$ in cathodic current efficiency, smoothness and metallic lustre. The EMIMBr/ZnBr ${ }_{2}^{-}$ ethylene glycol ternary systems were also studied with a 
water content of $30 \mathrm{ppm}$. The cathodic current efficiencies were all $100 \%$, even at a current density as high as $300 \mathrm{~A} \mathrm{~m}^{-2}$, in Lewis basic melts with an EG content of between 30 and 75 mol.- $\%$.

Abbott et al. studied the deposition of zinc from a $1: 2$ choline chloride $(\mathrm{ChCl}) / \mathrm{ZnCl}_{2}$ ionic liquid ${ }^{45}$ at $60^{\circ} \mathrm{C}$ and found deposits with a similar morphology to that shown by Sun. The optimum current density was found to be between 2 and $5 \mathrm{~A} \mathrm{~m}^{-2}$ and higher current densities led to powdery, non-adherent deposits. This is due primarily to the high viscosity and low conductivity of the choline based liquids. The current plating efficiency in this liquid was found to be effectively $100 \%$ and the deposition process was shown to be almost totally reversible with only the UPD material remaining on the surface.

The work of Iwagishi ${ }^{44}$ effectively uses a hybrid of a Type I and Type III eutectic. The present authors have studied the deposition of zinc from a number of glycol and urea based eutectics and found that the deposition of zinc can be significantly affected by the type of hydrogen bond donor used. ${ }^{46}$

\section{Zinc alloys}

While the deposition of zinc is technologically relatively simple, the deposition of zinc alloys is particularly difficult due primarily to the differences in redox potentials. In an ionic liquid the redox potentials of metals are shifted from the values expected from aqueous systems. This is due to the formation of chlorometallate anions and the thermodynamic difference in their reduction compared to the hydrated metal ions. Reports have been published on the deposition of $\mathrm{Zn}$ alloys with $\mathrm{Cu},{ }^{47-49} \mathrm{Cd},{ }^{50} \mathrm{Sn},{ }^{46,51} \mathrm{Co},{ }^{52} \mathrm{Fe},{ }^{53} \mathrm{Ni}^{53}$ and Te. ${ }^{54}$ Most of these are from Type $\mathrm{I} \mathrm{ZnCl}_{2} / \mathrm{EMIMCl}$ eutectics.

Deposition of the $\mathrm{Zn} / \mathrm{Co}$ and $\mathrm{Zn} / \mathrm{Fe}$ alloys from aqueous solutions produces an anomalous alloy where the less noble $\mathrm{Zn}$ is preferentially deposited to the other metal. In ionic liquids it is possible to deposit a variety of alloy compositions allowing either metal to be predominant depending upon the relative concentrations of the metals and the applied deposition potential. The $\mathrm{Zn} / \mathrm{Fe}^{53}$ system is interesting as the deposition of $\mathrm{Fe}$ occurs at a less negative potential to the $\mathrm{Zn}$. UPD of $\mathrm{Zn}$ on $\mathrm{Fe}$ occurs through a two-dimensional nucleation before bulk zinc deposition. Fe content was varied from 100 to $50 \%$ depending upon liquid composition. Similar results were found for $\mathrm{Zn}-\mathrm{Ni}$ alloys. Again a wide range or composition could be obtained with both amorphous and crystalline material. The alloy $\mathrm{Zn}_{21} \mathrm{Ni}_{5}$ could only be obtained by the addition of ethanol to the liquid.

Sun et $a l .^{55}$ also showed that ionic liquids could be used for the production of porous substrates by alloying zinc with certain metals. They showed that the deposition of $\mathrm{Zn}$ on $\mathrm{Pt}, \mathrm{Au}$ or $\mathrm{Ag}$ led to an alloy being formed with the substrate. Subsequent anodic dissolution of the zinc caused a porous substrate to be produced. These have potential applications in catalysis, fuel cells and sensors.

$\mathrm{Zn}-\mathrm{Sn}$ alloy coatings on mild steel substrates have been prepared using deep eutectic solvent electrolytes based on mixtures of choline chloride and ethylene glycol or urea. ${ }^{46}$ It was shown that zinc and tin can be electrodeposited from these liquids both individually and as alloys. It was also shown that the alloy morphology and composition could be changed by judicious choice of the ionic liquid. It was proposed that metal speciation affected metal reduction thermodynamics. The stability of colloidal solutions in ionic liquids allowed composite materials to be deposited and $\mathrm{Al}_{2} \mathrm{O}_{3}$ was used as an example. This could open a new avenue for the deposition of coatings with improved wear resistance. A range of deposit compositions have been produced with over $80 \% \mathrm{Zn}$ content possible. The processes have been scaled up to a large laboratory scale using an electrolyte volume of $10 \mathrm{~L}$ and plating $150 \times 80 \mathrm{~mm}$ mild steel cathodes. Figure 6 shows photographs of some $\mathrm{Zn} / \mathrm{Sn}$ samples prepared using this technique.

Ionic liquids offer numerous advantages for the deposition of alloys including; elimination of hydrogen embrittlement in $\mathrm{Zn}-\mathrm{Ni}$ alloys for aerospace applications, deposition of high $\mathrm{Zn}$ content coatings with $\mathrm{Sn}$, deposition of higher $\mathrm{Fe}$ content $\mathrm{Zn}-\mathrm{Fe}$ alloys than achievable by aqueous systems and replacement of the strong acids and alkalies or toxic complexants that are currently used by aqueous electrolytes with a lower environmental impact.

$\mathrm{Zn}$ based alloy coatings could be used to replace or improve a variety of coatings. Automotive requirements are either $\mathrm{Zn}-\mathrm{Ni}$ or $\mathrm{Zn}-\mathrm{Fe}$. Aeronautic requirements are $\mathrm{Zn}-\mathrm{Ni}$ with a good coefficient of friction, or $\mathrm{Zn}-\mathrm{Sn}$ with at least $70 \% \mathrm{Zn}$ content, otherwise the coating is too soft. $\mathrm{Ni}-\mathrm{Sn}$ alloys are resistant to corrosion and tarnishing, and are therefore potential replacements for decorative chromium.

\section{Other metals}

Numerous other metal deposition processes have been studied including $\mathrm{Cu}, \mathrm{Ag}, \mathrm{Co}$ and $\mathrm{Bi}$. A plethora of $\mathrm{Al}$ alloys have also been studied in imidazolium based chloroaluminates and a review of these has recently been published. ${ }^{56}$ Endres has also recently written a review on the deposition of semiconductors, ${ }^{14}$ primarily from eutectic based ionic liquids. None of these may seem technologically important, but one of the key advantages of ionic liquids is their ability to destabilise passive oxide films. This has the advantage that it allows direct electrolytic deposition onto an important range of substrates.

Magnesium and its alloys are very reactive and therefore their electroplating in aqueous solutions is hazardous. They are classified as water sensitive substrates from the electrodeposition point of view, and thus the importance of ionic liquids (IL) as nonaqueous electrolytes for electrodeposition. It is extremely difficult to coat magnesium electrochemically by any metal in aqueous solutions as it reacts extremely with water forming loose corrosion layers. The corrosion rate of $\mathrm{Mg}$ in the IL ChCl/urea is four orders of magnitude lower than that in the aqueous electrolyte used for $\mathrm{Zn}$ electrodeposition. Air and water stable ionic liquid $1 \mathrm{ChCl:2}$ urea has been successfully used as an electrolytic solvent for electrodeposition of $\mathrm{Zn}$ onto $\mathrm{Mg}$ alloys.

In the electrodeposition of metallic $\mathrm{Zn}$ layers onto $\mathrm{Mg}-\mathrm{RE}$ alloys in the ionic liquid $1 \mathrm{ChCl}: 2$ urea, the $\mathrm{Zn}$ coatings are uniform, dense and free of defects. $\mathrm{Zn}$ coated $\mathrm{Mg}$ alloys exhibit a corrosion behaviour similar to that of pure $\mathrm{Zn}$. An SEM example of this deposit is shown in Fig. 7. 


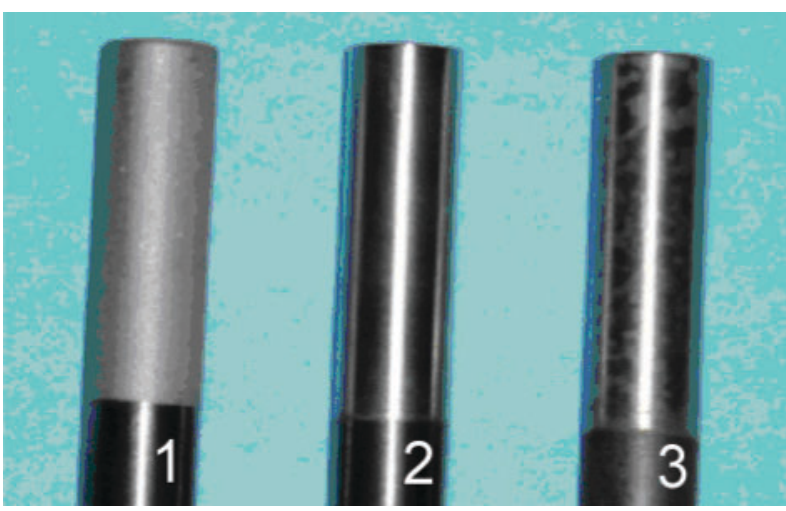

$115 \% \mathrm{Zn}-85 \% \mathrm{Sn}, 5 \mu \mathrm{m}$ thickness; 2 with diluent and brightener, $5 \mu \mathrm{m}$ thickness; 3 as 2, 6.7 $\mu \mathrm{m}$ thickness

6 Examples of some $\mathrm{Zn} / \mathrm{Sn}$ samples on XC38 steel prepared using $\mathrm{ChCl} / \mathrm{EG}$ eutectics at $55^{\circ} \mathrm{C}$

\section{Electrodissolution of metals}

\section{Electropolishing of stainless steel}

Electropolishing is the controlled corrosion of a metal surface to bring about a reduction in surface roughness and an increase in corrosion resistance of the components. Electropolishing pieces also decreases wear and increases lubricity in engines overcoming a major cause of failure. Since the first systematic study of electropolishing in $1930^{57,58}$ very little has changed in the commercial electropolishing process. An electrolyte based on concentrated phosphoric acid and sulphuric acid mixtures is still employed despite the difficulty of use and very poor current efficiency. A new process has been developed for electropolishing stainless steel using a choline chloride/ethylene glycol eutectic. ${ }^{59-61}$ The operating conditions are similar to the existing acid based solutions and represent simple drop-in replacement technology. Abbott et al. ${ }^{60}$ have shown that the electropolishing mechanism is fundamentally different in an ionic liquid to an aqueous acid solution. No passivating layer is formed on the electrode in an ionic liquid and this decreases the ohmic resistance of the cell. The process does not result in dealloying of the steel but corrosion tests on the polished pieces show that they are at least equivalent to the current technology. The process operates at a temperature of $30-50^{\circ} \mathrm{C}$ and typically uses a polishing regime of $3-5 \mathrm{~V}$ for $10 \mathrm{~min}$ making it similar to the current technology. One issue arising with aqueous polishing is the necessity to treat large quantities of waste acid containing high metal concentrations. A recycling protocol has been developed for the ionic liquid which involves the addition of aqueous solutions to precipitate the metal salts followed by filtration and then evaporation of the water. The overall process has several benefits including: non-acidic formulation, improved surface finish on cast pieces, fourfold improvement in current efficiency, reduced and simplified waste treatment, less gassing and metal waste is recoverable. The technology has been scaled up to 1000 L with Anopol Ltd.

The same liquid can also be applied to the electropolishing of high specification alloys that are currently inaccessible to acid based solutions. A variety of $\mathrm{Ni} / \mathrm{Co}$ alloys have been successfully polished on pilot plant scale. Preliminary results have also shown that some titanium based alloys can also be polished using ionic

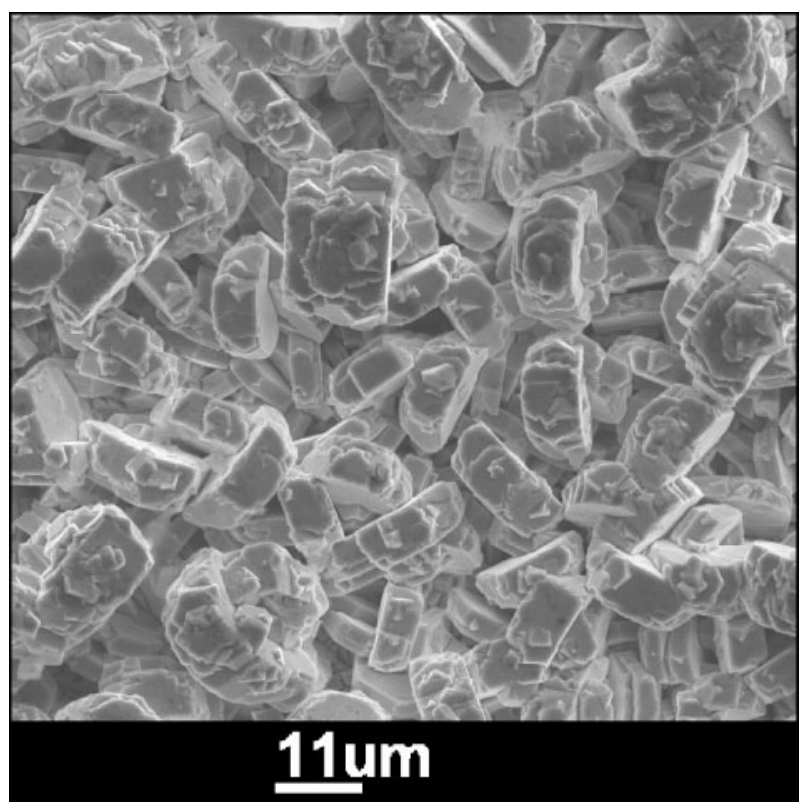

7 SEM of electrodeposited metallic $\mathrm{Zn}$ onto Mg-RE alloys in the ionic liquid 1ChCl:2 urea (deposited at constant current)

liquids and this is work currently being carried out by $\mathrm{C}$ Tech Ltd in the UK.

\section{Electroless coatings}

Electroless deposition can be split into two categories; catalytically activated deposition and immersion coatings. The former uses a reducing agent in solution whereas the latter relies of the galvanic potential difference between the ions in solution and the substrate. The former is particularly important for electroless $\mathrm{Ni}$ and $\mathrm{Cu}$ used extensively in the PCB industry, whereas the latter is primarily used for electroless $\mathrm{Ag}$, again in the PCB market.

The PCB fabrication technology has gone through significant changes over the last 20 years. This was mainly due to the limitation of using chlorinated and or fluorinated solvents in the fabrication process. As a result, certain photo polymer resist materials used for conductor imaging and solder masking could no longer be processed. The newer resists that are processed in alkaline solution did not withstand the high $\mathrm{pH}$ of the electroless $\mathrm{Cu}$ plating bath; direct electroless plating of conductor lines, as used in additive processing of PCBs, could no longer be performed. The PCB fabrication processes using additive technology ceased because of the lack of suitable materials. The introduction of ionic liquids as a new plating technology for electroless or electroplating offered a new opportunity for the reintroduction of additive technology.

\section{Electroless deposition of silver on copper}

A new process has been developed for the electroless (immersion) deposition of silver on to a copper substrate. ${ }^{62}$ The process is particularly designed for silver plating on multitrack circuit boards. The operating conditions are the same as the existing water based solutions and represent simple drop-in technology. The liquid used is a choline chloride ethylene glycol mixture containing silver chloride. The deposit formed is a porous nanocrystalline layer which acts as a good key 


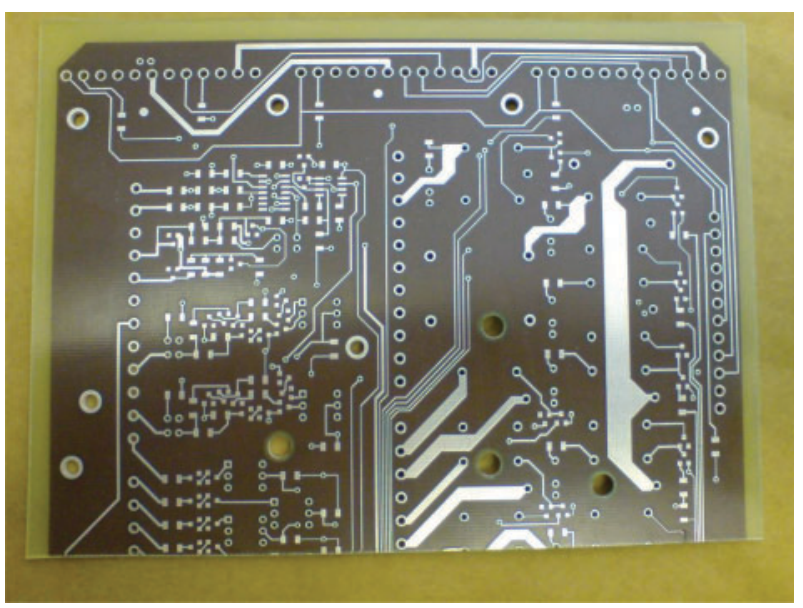

8 Example of silver coated printed circuit board produced using electroless immersion process in ionic liquid

for the solder. The authors believe that being porous also makes it possible to produce very thick coatings. The process has the following benefits: thick, bright, adherent silver layers possible, reduced light sensitivity of solution, decreased soldering temperature, uniform deposition rate, non-acidic and non-cyanide formulation. Details of this simple process have recently been published. ${ }^{62,63}$ The process is currently being scaled up by PW Circuits in Leicester, UK. An example of a silver coated board produced by this process is shown in Fig. 8.

\section{Electroless deposition of copper on aluminium}

A new process has been developed for the electroless (immersion) deposition of copper adhesion layers onto aluminium substrates. The process is designed to facilitate electrolytic coatings of other metals onto aluminium components. The operating conditions are very mild and the process is very simple. The thickness of the copper adhesion layer is controlled by exposure time but typically thin, even, adherent, homogeneous films can be deposited in a few minutes. The process is obtained by simple immersion of the substrate in a solution of metal ions. This process has the benefit that electrolytic plating on top of the copper ad-layer is easily accomplished using any other conventional electroplating process. For example, good adherent coatings $(10 \mu \mathrm{m})$ of $\mathrm{Ni}$ were achieved from an aqueous Watts bath on an $\mathrm{Al}$ rod plated with electroless $\mathrm{Cu}$ from the ionic liquid as shown in Fig. 9.

\section{Importance of ionic liquids}

Part of the objective of the IONMET project is the identification and development of techniques for control and recycling of materials to ensure close to zero environmental discharges. Risk analysis and possible contingencies are being studied and compared with the risks that can occur in the use of traditional chemical formulations. Evaluation procedures are normalised by governmental procedures and have to comply with national laws and European directives. Results of this task are being contrasted against recommendations of integrated pollution prevention and control. Integrated pollution prevention and control related with surface treatment activities will be implemented in the near

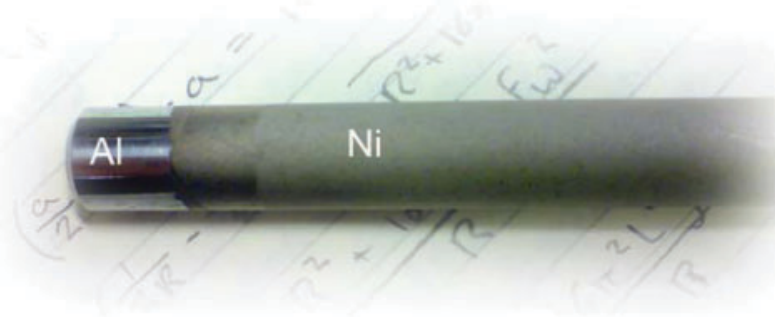

$910 \mathrm{~mm}$ diameter Al rod coated with electroless (immersion) $\mathrm{Cu}$ from IL solution and then adherent electrolytic $\mathrm{Ni}(10 \mu \mathrm{m})$ from conventional aqueous Watts Ni bath

future and will have a severe effect on industrial activities. A comprehensive assessment of the environmental impact of the use of ionic liquid solvents in metal finishing processes is being carried out, and targets will be set for the performance of treatment technologies. A detailed risk assessment analysis will be completed covering the use of the chemicals selected for each process to be studied and developed. Methods for removing and recovering salts and metal ion components from rinse baths to be recycled to plating baths are being assessed: ion exchange, sorption, extraction, evaporation. Technical and economic aspects will be covered. Maintenance of bath condition and determination of lifetime are also being investigated. Post treatment protocols are in evaluation, e.g. rinsing and drying procedures.

\section{Market opportunities}

There are a significant number of issues with the implementation of ionic liquids which need to take into account 100 years of history in plating and the reticence for change. The majority of the plating industry is not yet ready to use industrially non-aqueous electrolytes such as ionic liquids although the plant and handling differences are in most cases relatively minor. The acceptance of many SMEs of the technology shows that it is relatively easy to apply. There is little doubt that the short term target should concentrate on specialised application with high current revenue and acceptance of slightly higher costs. In general the ease of use should attract social acceptance relatively quickly.

\section{Conclusions}

While ionic liquids are in their infancy compared to aqueous electrochemistry significant breakthroughs have been made over the last 10 years. The advantages of using non-aqueous systems have led to a significant pull for nascent technology. The results discussed above show that there is significant cause for optimism that ionic liquids will soon breakthrough into commercial markets for applications such as the deposition of aluminium and chromium, the deposition of a range of metals onto water sensitive substrates, electropolishing of a variety of alloys and the electroless deposition of metals particularly in the PCB industry.

There are still significant questions that need to be addressed both from a fundamental and applied perspective, but close collaboration between academia and industry particularly across Europe has already led to significant strides forward over the past five years. A corresponding review in 10 years time will undoubtedly 
focus on the industrial applications of ionic liquids and will cover a far wider range of systems.

\section{Acknowledgements}

The authors thank all of the collaborators in the IONMET project but notably, Professor Patrick Benaben (ARMINES, St. Etienne, France), Dr Jacques Halut (Protection des Metaux, Paris, France), Fundacion Inasmet (San Sebastian, Spain) and $P W$ Circuits (Leicester, UK) for providing photographs of samples prepared by their processes.

\section{References}

1. A. K. Graham (ed.): 'Electroplating engineering handbook'; 1995, New York, Kluwer Academic.

2. P. Wasserscheid and T. Welton: 'Ionic liquids in synthesis', 2nd edn; 2008, Weinheim, Wiley-VCH Verlag.

3. K. R. Seddon: Proc. Int. George Papatheodorou Symp. (ed. S. Boghosian et al.), 131-135; 1999, Patras, Institute of Chemical Engineering and High Temperature Chemical Processes.

4. N. V. Plechkova and K. R. Seddon: Chem. Soc. Rev., 2008, 37, $123-150$.

5. J. S. Wilkes: ACS Symp. Ser., 2002, 818, 214

6. Y. Zhao and T. J. Vandernoot: Electrochim. Acta, 1997, 42, 3.

7. S. Zein El-Abedin and F. Endres: Chem. Phys. Chem., 2006, 7, 58.

8. F. Endres : Chem. Phys. Chem., 2002, 3, 144.

9. F. Endres: Z. Phys. Chem., 2004, 218, 255

10. D. R. MacFarlane, M. Forsyth, P. C. Howlett, J. M. Pringle, J. Sun, G. Annat, W. Neil and E. I. Izgorodina: Acc. Chem. Res., 2007, 40, 1165-1173.

11. H. Ohno (ed.): 'Electrochemical aspects of ionic liquids'; 2005, New York, John Wiley \& Sons.

12. M. C. Buzzeo, R. G Evans and R. G. Compton: Chem. Phys Chem., 2004, 5, 1106.

13. F. Endres and S. Zein El-Abedin: Phys. Chem. Chem. Phys., 2006, 8, 2101.

14. F. Endres, A. P. Abbott and D. R. MacFarlane: 'Electrodeposition of metals using ionic liquids'; 2008, Weinheim, Wiley VCH.

15. S.-I. Hsiu, J.-F. Huang, I.-W. Sun, C.-H. Yuan and J. Shiea: Electrochim. Acta, 2002, 47, 4367-4372.

16. A. P. Abbott, G. Capper, D. L. Davies, H. Munro, R. Rasheed and V. Tambyrajah: Chem. Commun., 2001, 2010.

17. Y.-F. Lin and I.-W. Sun: Electrochim. Acta, 1999, 44, 2771 ,

18. A. P. Abbott, G. Capper, D. L. Davies, H. Munro and R. Rasheed: Inorg. Chem., 2004, 43, 3447.

19. F. H. Hurley and T. P. Weir: J. Electrochem. Soc., 1951, 98, 207.

20. W. G. Xu, X-M. Lu, J. Z. Yang, J-S. Gui, J. Z. Yang, Chinese J. Chem., 2006, 24, 331-335.

21. J. Z. Yang, W. G. Xu, P. Tian and L.-L. He: Fluid Phase Equil., 2003, 204, 295-302.

22. A. P. Abbott, G. Capper, D. L. Davies and R. Rasheed: Chem. Eur. J., 2004, 10, 3769

23. A. P. Abbott, G. Capper, D. L. Davies, R. Rasheed and V. Tambyrajah: Chem. Commun., 2003, 70.

24. A. P. Abbott, D. Boothby, G. Capper, D. L. Davies and R. Rasheed: J. Am. Chem. Soc., 2004, 126, 9142.

25. A. P. Abbott, G. Capper, B. G. Swain and D. A. Wheeler: Trans. $I M F, 2005, \mathbf{8 3}, 51$.

26. http://www.ionmet.eu/

27. E. Peled and E. Gileadi: J. Electrochem. Soc., 1976, 123, 15-19.

28. L. Simanavicius: Chemija, 1990, 3, 3-30.
29. F. Lantelme, H. Alexopoulos, M. Chemla and O. Haas: Electrochim. Acta, 1988, 33, 761.

30. F. H. Hurley and T. P. Weir: J. Electrochem. Soc., 1951, 98, 207.

31. H. L. Chum, V. R. Koch, L. L. Miller and R. A. Osteryoung: J. Am. Chem. Soc., 1975, 97, 3264.

32. J. S. Wilkes, J. A. Levisky, R. A. Wilson and C. L. Hussey: Inorg. Chem., 1982, 21, 1263.

33. J. Robinson and R. A. Osteryoung: J. Electrochem. Soc., 1980, 127, $122-128$.

34. B. J. Welch and R. A. Osteryoung: J. Electroanal. Chem., 1981, 118, 456-466.

35. P. K. Lai and M. Skyllas-Kazacos: J. Electroanal. Chem., 1988, 248, 431-440.

36. Q. Liao, W. R. Pitner, G. Stewart, C. L. Hussey, and G. R. Stafford: J. Electrochem. Soc., 1997, 144, 936-943.

37. A. P. Abbott, C. A. Eardley, N. R. S. Farley, G. A. Griffith and A. Pratt: J. Appl. Electrochem., 2001, 31, 1345-1350.

38. http://www.hcat.org/

39. A. P. Abbott, G. Capper, D. L. Davies, R. K. Rasheed, J. Archer and C. John: Trans. IMF, 2004, 82, 14

40. M. S. Sitze, E. R. Schreiter, E. V. Patterson and R. G. Freeman: Inorg. Chem., 2001, 40, 2298.

41. S.-I. Hsiu, J.-F.Huang, I.-W. Sun, C.-H. Yuan and J. Shiea: Electrochim. Acta, 2002, 47, 4367-4372.

42. Y.-F. Lin and I.-W. Sun: Electrochim. Acta, 1999, 44, 2771.

43. K. Koyama, T. Iwagishi, H. Yamamoto, H. Shirai and H. Kobayashi: Electrochemistry, 2002, 70, 178-182.

44. T. Iwagishi, H. Yamamoto, K. Koyama, H. Shirai and H. Kobayashi: Electrochemistry, 2002, 70, 671-674.

45. A. P. Abbott, G. Capper, D. L. Davies, H. Munro, R. Rasheed and V. Tambyrajah: in 'Ionic liquids as green solvents: progress and prospects', (ed. R. D. Rogers and K. R. Seddon), ACS Symposium Series, 439; 2003, Washington: American Chemical Society.

46. A. P. Abbott, G. Capper, K. J. McKenzie and K. S. Ryder: J. Electroanal. Chem., 2007, 599, 288.

47. N. Koura, T. Endo and Y. Idemoto: J. Non-Cryst. Solids, 1996, 205, 650 .

48. L. Simanavicius, A. Stakenas and A. Starkis: Electrochim. Acta, 1997, 42, 1581

49. Y. Lin and I. Sun: Electrochim. Acta, 1999, 44, 2771.

50. J.-F. Huang and I.-W. Sun: J. Electrochem. Soc., 2002, 149, E348.

51. J.-F. Huang and I.-W. Sun: J. Electrochem. Soc., 2003, 150, E299.

52. A. P. Abbott, G. Capper, D. L. Davies, R. Rasheed and V. Tambyrajah: Trans. IMF, 2001, 79, 204

53. J.-F. Huang and I.-W. Sun: J. Electrochem. Soc., 2004, 151, C8.

54. M.-C. Lin, P.-Y. Chen and I.-W. Sun: J. Electrochem. Soc., 2001, 148, C653.

55. F. H. Yeh, C. C. Tai, J. F. Huang and I.-W. Sun: J. Phys. Chem. B, 2006, 110B, 5215

56. A. P. Abbott and K. J. McKenzie: Phys. Chem. Chem. Phys., 2006, 8, 4265-4279.

57. H. Figous and P. A. Jacquet: French patent no. 707526, 1930

58. D. Landolt: Electrochim. Acta, 1987, 32, 1 .

59. A. P. Abbott, G. Capper, B. Swain and D. Wheeler: Trans. IMF, $2005,82,51$

60. A. P. Abbott, G. Capper, K. J. McKenzie and K. S. Ryder: Electrochim. Acta, 2006, 51, 4420-4425.

61. A. P. Abbott, G. Capper, K. J. McKenzie, A. Glidle and K. S. Ryder: Phys. Chem. Chem. Phys., 2006, 8, 4214.

62. A. P. Abbott, S. Nandhra, S. Postlethwaite, K. S. Ryder and E. L. Smith: Phys. Chem. Chem. Phys., 2007, 9, 3735-3743.

63. A. P. Abbott, J. Griffith, S. Nandhra, C. O'Connor, S. Postlethwaite, K. S. Ryder and E. L. Smith: Surf. Coat. Technol., 2008, 202, 2033-2039. 